\title{
Erratum to: The effect of crown architecture on dynamic amplification factor of an open-grown sugar maple (Acer saccharum L.)
}

Cihan Ciftci · Sergio F. Brena $\cdot$ Brian Kane $\cdot$ Sanjay R. Arwade

Published online: 20 June 2013

(C) Springer-Verlag Berlin Heidelberg 2013

\section{Erratum to: Trees}

\section{DOI 10.1007/s00468-013-0867-z}

In Eq. 9 of the original publication, the square root on the denominator of the right-hand term was inadvertently omitted. The correct equation is provided below.

$R d=\frac{u_{0}}{\left(u_{s t}\right)_{0}}=\frac{u_{0}}{P_{0} / k}=\frac{1}{\sqrt{\left[1-\left(\omega / \omega_{n}\right)^{2}\right]^{2}+\left[2 \zeta\left(\omega / \omega_{n}\right)\right]^{2}}}$

The online version of the original article can be found under doi:10.1007/s00468-013-0867-z.

C. Ciftci $(\bowtie)$. S. F. Brena · S. R. Arwade

Department of Civil and Environmental Engineering,

University of Massachusetts, Amherst, MA, USA

e-mail: cihanc58@gmail.com

B. Kane

Department of Environmental Conservation,

University of Massachusetts, Amherst, MA, USA

e-mail: bkane@eco.umass.edu 